\title{
1 Influence of dual-tasking with different levels of attention diversion on 2 characteristics of the movement-related cortical potential
}

3 Susan Aliakbaryhosseinabadi ${ }^{\mathrm{a}}$, Ernest Nlandu Kamavuako ${ }^{\mathrm{a}}$, Ning Jiang ${ }^{\mathrm{b}}$, Dario Farina ${ }^{\mathrm{c}}$ and Natalie

$4 \quad$ Mrachacz-Kersting ${ }^{\mathrm{a}}$

$5{ }^{a}$ Center for Sensory-Motor Interaction (SMI), Department of Health Science and Technology, Aalborg University,

6 Aalborg, Denmark

$7 \quad$ bepartment of Systems Design Engineering, University of Waterloo, Waterloo, Canada

8

$9{ }^{\mathrm{c}}$ Department of Bioengineering, Imperial College London, SW7 2AZ London, UK

$10 *$ Corresponding author:

11 Natalie Mrachacz-Kersting

12 Center for Sensory-Motor Interaction (SMI)

13 Department of Health Science and Technology

14 Aalborg University

15 Fredrik Bajers Vej 7 D3

169220 Aalborg $\varnothing$

17 Denmark

18 Phone: 004599407571

19 Email: nm@hst.aau.dk 
1

2

3

4

5

6

Dual tasking is defined as performing two tasks concurrently and has been shown to have a significant effect on attention directed to the performance of the main task. In this study, an attention diversion task with two different levels was administered while participants had to complete a cue-based motor task consisting of foot dorsiflexion. An auditory oddball task with two levels of complexity was implemented to divert the user's attention. Electroencephalographic (EEG) recordings were made from nine single channels. Event-related potentials (ERPs) confirmed that the oddball task of counting a sequence of two tones decreased the auditory P300 amplitude more than the oddball task of counting one target tone among three different tones. Premovement features quantified from the movement-related cortical potential (MRCP) were changed significantly between single and dual-task conditions in motor and fronto-central channels. There was a significant delay in movement detection for the case of single tone counting in two motor channels only (237.1 to $247.4 \mathrm{~ms}$ ). For the task of sequence counting, motor cortex and frontal channels showed a significant delay in MRCP detection (232.1 to $250.5 \mathrm{~ms}$ ). This study investigated the effect of attention diversion in dual-task conditions by analysing both ERPs and MRCPs in single channels. The higher attention diversion lead to a significant reduction in specific MRCP features of the motor task. These results suggest that attention division in dual-tasking situations plays an important role in movement execution and detection. This has important implications in designing real-time brain-computer interface systems.

Keywords: Attention, Dual-tasking, movement-related cortical potential, brain-computer interface, Auditory oddball 


\section{Introduction}

Brain-Computer interface (BCI) systems in the neuro-rehabilitation field aim to reduce disability of patients by using brain signals to control a device or a computer. Changes in these signals due to internal factors, such as attention variations, or external factors, such as electrical stimulation, influence the performance of BCI systems. Therefore, there have been several previous attempts to quantify the impact of these parameters on BCI systems (da Silva-Sauer et al., 2015; Diez et al. 2015; O'Sullivan et al., 2015). For example, during execution of challenging mental tasks, spectral features of EEG signals were used to detect changes in fatigue, frustration and attention on a single trial basis (Myrden and Chau, 2017). The classification accuracy of these three mental states was on average 71.6-84.8\%, making them feasible to use in an online BCI system. During a motor task, where participants are asked to focus their attention on the kinesthetics of their legs moving during a passive pedaling task, attention and inattention (mind wandering) could be classified using spectral features of EEG signals with an accuracy of 61 to $68 \%$ (Melinscak et al., 2016). Besides frequency features, the characteristics of the waveform of the P300 have also been used to reveal alterations in attention (Huang et al., 2015; Linden, 2005). The P300, a positive deflection in the EEG signal first described by Sutton et al.(Sutton et al., 1965), is an event-related potential that is time locked to a visual or auditory stimulus. Although it has been used with success in BCI applications, specifically for communication and environmental control (Krusienski et al., 2008), it is commonly implemented for the quantification of attention and working memory (Huang et al., 2015; Linden, 2005). It may thus be an ideal signal modality to better understand the effects that attention has on the performance of BCI systems.

In the last decade, we have worked towards the design of an online associative BCI system for the rehabilitation of gait in stroke patients. Here the movement related cortical potential (MRCP) elicited by attempted dorsiflexion movements of the affected ankle joint is detected and used to control the activation of an electrical stimulator that provides a single stimulus to the deep branch of the common peroneal nerve. The nerve activation is timed such that the generated afferent signal arrives at the motor cortex during the peak negative (PN) phase of the MRCP. With this intervention, we have shown significant plasticity induction at the motor cortex, accompanied by functional changes in chronic and sub-acute stroke patients (Mrachacz-Kersting et al., 2017; Mrachacz-Kersting et al., 2016). The advantage of using the MRCP as the control signal in an associative $\mathrm{BCI}$ is that it can be detected approximately 1-2 seconds prior to movement execution and that the time of the peak negative phase is stable within a patient and session, ensuring precise timing in eliciting the afferent volley. To allow this system to be used in the clinical setting we have worked towards minimizing the number of electrode sites required for reliable detection of the MRCP (Jochumsen et al., 2014). In addition, since it is known that attention can modulate plasticity induction (Stefan et al., 2004), we have investigated the effects of artificially imposed attention shifts on the detection of the MRCP as part of the associative BCI using both spectral and time features (Aliakbaryhosseinabadi et al., 2015; Aliakbaryhosseinabadi et al., 2017; Aliakbaryhosseinabadi et al., 2017).

The aim of this study was to quantify the specific electrode sites and features of the MRCP that are necessary to detect changes in attention during the use of a MRCP-based BCI. Further, we investigate whether it is possible to differentiate between different levels of attention to a target task. For this purpose, healthy participants were asked to perform either a primary task 
consisting of a visually cued overt (real) foot movement or a dual task with two levels of complexity consisting of the primary task and a secondary task comprised of counting the number of a defined target in an auditory oddball cue. The complexity of the secondary task was altered by varying the sequence of tones that had to be counted from identifying a single tone (simple dual task (SDT)) to a sequence of tones (complex dual task (CDT)). The experimental procedure is illustrated in Fig.1. MRCP features, extracted from nine EEG channels, were analyzed to quantify changes in movement preparation and their effects on the detection accuracy. The changes in the level of attention were quantified by the amplitude of the P300. We hypothesized that the dual task condition would result in a decreased P300 amplitude and a decreased performance of the main task as quantified by a delayed onset and decreased amplitude of the electromyography (EMG) signal of the prime mover (Tibialis anterior). We further hypothesized that the amplitude of $\mathrm{PN}$ of the MRCP would decrease and the variability of the MRCP in the preparation phase increase, thus decreasing the detection accuracy of the BCI system.

\section{Results}

\subsection{ERP analysis and task performance}

The results of the comparison of the control levels between the two groups indicated that the P300 amplitude was not significantly different for either the visual cue $\left(\mathrm{F}_{(1,22)}=0.9, \mathrm{P}>0.05\right)$ or for the auditory task $\left(\mathrm{F}_{(1,22)}=1.2, \mathrm{P}>0.05\right)$. However, in the dual-task condition the P300 amplitude was significantly different between the two groups of difficulty only in the task with the auditory oddball cue $\left(\mathrm{F}_{(1,22)}=14.6, \mathrm{P}<0.004\right)$ but not in the visual cue $\left(\mathrm{F}_{(1,22)}=0.01, \mathrm{P}>0.05\right)$. Fig. 2e and 2f illustrate the average $\mathrm{P} 300$ amplitude across all participants and groups for both the visual and the auditory cue.

The P300 amplitude of the task based on the auditory oddball cue was significantly increased only for the control versus the CDT $\left(F_{(1,11)}=29.9, P<0.001\right)$. According to the visual cue, the P300 amplitude was decreased from control to CDT or SDT level but not-significantly as illustrated in Fig. 2.

The performance of SDT was significantly better than the CDT as quantified by a lower oddball error $\left(\mathrm{F}_{(1,22)}=25.5, \mathrm{P}<0.001\right.$; SDT: $6.4 \pm 6.8 \%$, CDT: $28.5 \pm 24.1 \%$ ). The reaction time was significantly increased only for the control versus the CDT level $\left(\mathrm{F}_{(1,1)}=21.9, \mathrm{P}<0.004\right.$; control:212 $\pm 12.6 \mathrm{~ms}$, CDT: $\left.254 \pm 16.5 \mathrm{~ms}\right)$. The reaction time of CDT was also higher than SDT condition but not-significantly.

The mean correlation coefficients of all trials within the control block showed no statistically significant difference compared to those of the SDT $\left(\mathrm{F}_{(1,11)}=1, \mathrm{P}>0.05\right)$ and $\mathrm{CDT}\left(\mathrm{F}_{(1,11)}=3.1, \mathrm{P}>0.05\right.$, two-way rmANOVA). This indicates that the participants performed the main task of dorsiflexion in a similar manner. However, the EMG mean correlation coefficients were significantly higher for the SDT $\left(\mathrm{F}_{(1,22)}=19.5, \mathrm{P}<0.004 ; 0.76 \pm 0.08\right)$ compared to the CDT level $(0.6 \pm 0.14)$.

\subsection{Peak negativity comparison}

Fig. 3 illustrates the average MRCP from nine single channels in the single and dual-task conditions for both levels of task difficulties. The motor cortex and fronto-midline channels show more significant differences between the control and dual- 
task both for SDT and CDT. Two-way rmANOVA revealed no significant interaction between movement blocks and task demand for all channels. Statistical analysis for the Control-CDT experiment demonstrated a significant difference between these two levels in $\mathrm{Cz}\left(\mathrm{F}_{(1,11)}=19, \mathrm{P}=0.002\right)$. In the Control-SDT experiment, none of the channels represented significant differences from control to SDT level. In spite of the task demand effect, movement blocks revealed no statistical changes in any of the channels in both experiments $(\mathrm{P}>0.05)$. No significant variations were found in time of peak negativity measurements $(\mathrm{P}>0.05)$. Fig. 3 shows that the time of the negative peak in the MRCP signals was similar in different movement blocks and also in both task demands.

\subsection{Pre-movement amplitudes}

Between the two extracted pre-movement amplitudes, the second negativity drift was significantly different based on the task demand in the control-CDT experiment in channels of $\mathrm{FCz}\left(\mathrm{F}_{(1,1)}=14.4, \mathrm{P}=0.003\right), \mathrm{C} 1\left(\mathrm{~F}_{(1,11)}=14.9, \mathrm{P}=0.003\right), \mathrm{C} 2$ $\left(F_{(1,11)}=15.6, P=0.002\right)$ and $C 4\left(F_{(1,11)}=14.8, P=0.003\right)$ and in the control-SDT experiment in $C 2\left(F_{(1,11)}=18.3, P=0.001\right)$ (Table 1).

\subsection{Pre and post phase slopes}

Slopes in the range of one second before time of peak negativity to this point were different between the two task demands in both experiments (Fig. 3). This was similar for the three movement blocks. However, the slopes in the range of 2 seconds before time of peak negativity to this point look different particularly in the Control-CDT. Interestingly, statistical analysis revealed that in this experiment both slopes significantly decreased in the $\mathrm{CDT}$ in channels $\mathrm{Cz}\left(\mathrm{F}_{(1,11)}=17.5, \mathrm{P}=0.002\right)$ and $\mathrm{C} 4\left(\mathrm{~F}_{(1,11)}=35.7, \mathrm{P}<0.001\right)$. However, in the SDT condition, none of the nine selected channels represented significant differences $(\mathrm{P}>0.05)$. None of the pre-phase slopes are statistically different among the movement blocks $(\mathrm{P}>0.05)$. A summary of the significantly different channels are presented in Table 1.

No significant differences were found for the post-phase slope based on both dependent factors $(\mathrm{P}>0.05)$.

\subsection{Pre-movement variability}

Pre-movement variability was compared in three time-domains and none of these were significantly different between the Control-SDT and the Control-CDT experiment $(\mathrm{P}>0.05)$.

\subsection{Movement detection factors}

RMANOVA yielded significant differences in detection latency between the two levels of the control-CDT experiment in channels Fz $\left(F_{(1,11)}=16.4, P=0.002\right), C 3\left(F_{(1,11)}=29.2, P<0.001\right), C 1\left(F_{(1,11)}=17.1, P=0.002\right), C z\left(F_{(1,11)}=57.9, P<0.001\right), C 2$ $\left(F_{(1,11)}=23.1, P<0.001\right)$ and $\mathrm{CPz}\left(\mathrm{F}_{(1,11)}=19, \mathrm{P}=0.001\right)$. The TPR was changed significantly between the two levels of the control-CDT in channels $\mathrm{C} 1\left(\mathrm{~F}_{(1,11)}=57.9, \mathrm{p}<0.001\right), \mathrm{Cz}\left(\mathrm{F}_{(1,11)}=36.5, \mathrm{P}<0.001\right), \mathrm{C} 2\left(\mathrm{~F}_{(1,11)}=62.1, \mathrm{P}<0.001\right)$ and $\mathrm{C} 4$ $\left(F_{(1,11)}=16.9, P=0.002\right)$. However, neither detection latency nor TPR was changed significantly between two levels of control- 
1 SDT. None of the detection parameters were significantly different for successive movement blocks. These results are 2 presented in Table 2.

\section{3. Discussion}

4 The present study compared the effect of attention diversion on MRCP parameters during dual- task performance while the difficulty of the secondary task was altered. MRCP preparation parameters in the second (late) negativity drift and premovement slopes were attenuated by the amount of attention to the primary and secondary task, which significantly affected detection of the MRCP. Our hypothesis that preparation for the primary (main) task is significantly affected when performed with the secondary task was thus confirmed. This has important implications for the performance of BCI systems designed for neuromodulation because the detection accuracy will decline under alterations in attention (Aliakbaryhosseinabadi et al., 2017; Aliakbaryhosseinabadi et al., 2017). Thus algorithms that can detect shifts in attention may be needed to adapt the detection. On the other hand, it is well known that attention can modulate cortical plasticity (Conte et al., 2007; Stefan et al., 2004). A decrease in the attention to the task may influence the induced plasticity and be detrimental for the rehabilitation intervention (Ziemann et al., 2008).

Electrode sites located over the motor-cortex area showed a greater attenuation in MRCP parameters compared to those located over the parietal and frontal lobe. Previous studies (Lin et al., 2011; Stopford et al., 2012) have shown that due to competition in dual task conditions for task resources such as motor components and attention, motor planning and motor execution can alter the effect of attention on frontal lobe activation. In the current study, the auditory oddball served as the distractor to divert attention from the main task, which was comprised of a dorsiflexion movement. Since movement activates cortical sites located within the motor and fronto-motor cortex it was expected that channels located here would present with the most significant changes in MRCP features and movement detection factors as compared to the frontal channels. The number of electrodes in clinical BCIs should be as low as possible to reduce factors such as costs and set-up time. One single channel over the motor cortex is sufficient for single-trial detection of a palmar grasp in EEG-based BCIs with an average accuracy of $78 \%$ (Jochumsen et al., 2015). In the current study, we further show that attentional changes may be reliably detected from channels located over the motor cortex. Thus, it may be feasible to use only a single (or a few) channel for both movement detection and detection of shifts in attention.

The most important outcome of this study is the effect on movement preparation with different levels of attention changes. Previously, only one study has investigated MRCP differences in the motor preparation phase between self-paced regular, alternating and random hand movements (Dirnberger et al., 2000). In that study, the regular task had the smallest MRCP amplitude particularly in the range of [1000 500] ms prior to the movement onset. The authors argue that, more attention and memory is applied in the random or alternating tasks (Dirnberger et al., 2000). Our study revealed that the preparation for the main task in the dual-task procedure was reduced compared to the single task performance, especially in electrode locations around the motor cortex. This may be related to the effect of executive function, which refers to the cognitive processes in 
1 concurrently, cognitive processing will be enhanced but this effect would be more enhanced for the cognitive skills related to

2 the novel and complex task (Montani et al., 2014). The evidence for this claim is the pre-execution MRCP parameters

3 extracted from midline and motor cortex channels, which showed a reduction in preparation for the main movement 4 particularly in the complex oddball.

5 Another consideration is the amount of attention applied in the dual-task in comparison to the single task. When the attention 6 level to a specific task is reduced, the movement preparation/execution will also decrease. According to the auditory P300 7 analysis (Fig.2), the attention to the auditory cue was increased as seen by the P300 amplitude increment while the visual cue 8 required less attention in the dual-task (Nash and Fernandez, 1996). Therefore, more attention was allocated to the secondary task likely with a concomitant decrease of motor cortex inhibition during the main task preparation and execution (Bruckmann et al., 2012).

According to previous reports (Hoffman et al., 1985; Kida et al., 2004), in dual-tasks the P300 amplitude decreased since performing a dual-task is more difficult than single task execution. Thus in the current study, a reduction and attenuation of the P300 amplitude was expected (Jeon and Polich 2003; Oknina et al. 2011; Polich 1987). However, in our study the dualtask execution resulted in an increment in the auditory P300 amplitude. It is known that the P300 amplitude is influenced by task difficulty and task emphasis (Kok, 2001), which may explain the discrepancy between our results and those of previous studies. In the current study, the P300 enhancement could very well have resulted from certain salient properties of the eliciting stimulus and not by an increased internal cognitive demand. In the level of the single task, performers were only required to attend to the main task, although in the dual-task condition they attended to two tasks simultaneously. In this study, the auditory oddball is thus the new task for them and more attention will likely be allocated to this task. Thus, visual attention will be reduced and diverted to the auditory cue as also shown in Fig.2. According to the correlation of the EMG envelope, reduction of visual attention had no effect on level of movement contraction but it influenced movement preparation as premovement factors were significantly changed between control and diverted attention levels.

\subsection{Effect of task repetition}

One of the aims of this study was to quantify the effect of task repetition both in the single and dual task condition. Task/stimuli repetition that is called habituation is one way to learn a task and thus will enhance performance (Grill-Spector et al. 2006). Based on the Hebbian principle (Hebb 2002), task learning strengthens the routs among activated neurons and consequently induces neuroplasticity. Habituation changes the template of activated neurons because the area of these neurons expands with task performance (Pascual-Leone et al., 1994). Due to this reason BCI performance improved by learning the new skills (Casimo et al., 2017; Teillet et al., 2016). According to this, EEG patterns used to control BCIs such as the P300 amplitude are decreased with stimuli repetition (Katayama and Polich, 1999; Polich, 2007) and the negativity of the MRCP is increased (Falvo et al., 2010; Falvo et al., 2011) during repetitive simple tasks. 
1 processing, represents the value of resources allocated to a task (Kida et al., 2004; Murray and Janelle, 2007). In the current

2 study, repetition did not have significant effects either in the single or in the dual task. One of the possible reasons may be 3 related to the task complexity and task experience during movement repetition. According to Pineda et al. (2003) the learning

$4 \quad$ process needs more time when the task needs more control.

\section{$5 \quad 3.2$ Study limitations}

6 In this study, EEG signals under attention diverted conditions were recorded and analyzed offline. For clinically-viable BCI 7 systems, in the future we will investigate the influence of attention in the online mode. For this purpose, it may be required to 8 analyze EEG signals not only in the time domain (MRCP features) but also in the frequency domain to add more information 9 about attention distribution in different brain regions (Melinscak et al., 2016; Myrden and Chau, 2017). A model of 10 classification with acceptable accuracy (at least higher than chance level) should be defined to classify attention status in both 11 healthy participants and patients with central nervous system insults, such as following a stroke. Since the latter group is often 12 limited in their motor performance, imagery of the movement needs to be included.

\section{Experimental Procedure}

\subsection{Participants}

Twenty-four healthy participants (12 females, 12 males) subdivided into two groups of 12 participants with gender match (mean ages 23.5 \pm 3.4 and 24.25 \pm 3.5 ) were included in the experiment. Dividing the subjects into two groups reduce the effect of experimental habituation on the results. All participants were without hearing abnormality and neurological disease. The experiment was approved by the local ethical committee for the region Northern Jutland (N-20130039).

\subsection{Experimental setup}

Twenty-eight mono-polar EEG signals were recorded using an active EEG electrode system (g. GAMMAcap ${ }^{2}$, Austria) and g.USBamp amplifier (gTec, GmbH, Austria) from AF3, AFz, AF4, F3, F1, Fz, F2, F4, FC3, FC1, FCz, FC2, FC4, C3, C1, $\mathrm{Cz}, \mathrm{C} 2, \mathrm{C} 4, \mathrm{CP} 3, \mathrm{CP} 1, \mathrm{CPz}, \mathrm{CP} 2, \mathrm{CP} 4, \mathrm{P} 3, \mathrm{P} 1, \mathrm{Pz}, \mathrm{P} 2, \mathrm{P} 4$ based on the standard international 10-20 system. The ground electrode was placed on FP1 while the reference electrode was on the right earlobe. Bipolar surface electromyography (EMG) signals were placed on the tibialis anterior muscle of the dominant foot to determine movement onset. All signals were sampled at $256 \mathrm{~Hz}$ with 16 bits accuracy.

\subsection{Paradigms and tasks}

Each participant was seated in a comfortable chair that was approximately one meter away from a digital computer screen while their right and left legs were placed on a step with the knee joint flexed $90^{\circ}$. The visual experimental cue was shown on the digital screen while an auditory cue was played via a conventional headphone. Fig. 1 illustrates the experimental paradigm. Participants were randomly assigned to either the simple or the complex task. All participants were asked to complete three 
1 blocks of a single-task (ankle dorsiflexion) and three blocks of a dual-task (ankle dorsiflexion and an auditory oddball task).

2 Each block contained a total of 30 trials of dorsiflexion timed to a visual cue followed by a rest period of approximately 4 3 min.

$4 \quad$ The dorsiflexion task: participants had to complete a dorsiflexion task during five phases of a visual cue that were defined as 5 focus, preparation, execution, hold and rest time (Fig.4a). After a random period of 2-3 seconds of the focus time, a schematic 6 in the form of a ramp with a moving cursor appeared on the screen. After the cursor traveled along the ramp for two seconds, 7 it reached an upward turn. At this point participants had to perform a ballistic ankle dorsiflexion of their dominant foot and sustain it for two seconds, followed by a rest phase with a random duration of 3-5 seconds

$9 \quad$ The auditory oddball task: The auditory oddball cue differed between the two groups of participants. In the simple oddball 10 task group, participants had to count the number of one of three tones played during the experimental block. They heard a frequent $500 \mathrm{~Hz}$ tone named low pitch which was randomized with the probability of $60 \%$ with a $1200 \mathrm{~Hz}$ tone called middle pitch and a $1900 \mathrm{~Hz}$ tone named high pitch, each with the probability of 20\% (Fig. 4b). In the complex oddball task group, participants had to count the number of a special sequence of tones combined with the same probability. The target sequence was either the number of times the middle pitch appeared after the low pitch, the number of high pitch played after the low pitch or the number of low pitch heard after the low pitch. In each block, participants had to count one of these sequences and report it at the end of the block. The auditory oddball cue commenced at the same time as the visual cue and had a randomized inter-stimulus interval (ISI) of 2-3 s. All auditory cues were played with a duration of $200 \mathrm{~ms}$ and had the same sound pressure level of $75 \mathrm{~dB}$ and $5 \mathrm{~ms}$ rise/fall time. The number of auditory oddball stimuli was random among different blocks as the ISI was selected randomly. On average, 135 oddball tones were played per block.

Depending on the group, the participants had to perform one of the following two levels of task complexity in the dual-task block:

1. Simple Dual Task (SDT): This group of participants had to perform ankle dorsiflexion based on the visual cue and concomitantly attend to the sounds heard from the headphone. They were asked to count the number of occurrences of one of the oddball tones. The type of the target tone (the tone had to be reported at the end of each block) was altered among the three blocks to avoid habituation and could be middle, low or high pitch. within each block. The oddball task of this group was to determine the number of a special sequence of oddball tones. The type of the target sequence (the sequence had to be counted and reported at the end of block) was different among the three blocks and could be low pitch-middle pitch, low pitch-high pitch or low pitch-low pitch. 
1 sounds via the headphone but they were asked to focus only on the movement performance not on the sounds. Thus, they

2 were instructed to attend only to the execution of dorsiflexion.

\subsection{Analysis of event-related potentials and oddball error}

Among the outputs of the three midline channels $\mathrm{Fz}, \mathrm{Cz}$ and $\mathrm{Pz}$ used in previous studies for ERP analysis (Neuhaus et al. 2007; Raij et al. 2003), channel Cz was selected as it was demonstrated that this channel can distinguish between target and non-target stimuli by generating larger P300 amplitudes (Xu et al., 2013). The amplitude of the P300 component of the ERP was extracted in the time window [-100 700] ms where $0 \mathrm{~ms}$ was the oddball stimuli onset. For the visual cue, zero was the time when the cursor commenced to move across the screen. The P300 amplitude was defined as the maximum value in this time range. The same method was used to extract the P300 amplitude for both the visual and auditory cue.

The performance was measured based on both the auditory and the visual task. For the auditory task, the number of errors in counting the target tone or sequence of tones in both types of dual tasking was considered as the performance indicator. For the visual task, the reaction time defined as the difference between real movement onset obtained from the tibialis anterior EMG signals with the expected onset based on the cue was considered as the performance criteria.

To investigate differences in how the participants performed the visual task, the correlation of EMG signals were computed in each block of movements. EMG signals were rectified and low pass filtered with a cut-off frequency of $10 \mathrm{~Hz}$ to obtain the EMG envelope. A correlation matrix was then calculated for all aligned single EMG trials in each block. Finally, the mean of the correlation values among all trials of each block was computed.

\subsection{MRCP analysis}

Continuous EEG signals were filtered in the frequency range [0.05 10] Hz using a $2^{\text {nd }}$ order band-pass Butterworth filter. Five Midline channels (Fz, FCz, Cz, CPz and Pz) and four other motor cortex channels (C3, C1, C2 and C4) were selected for signal analysis and feature extraction. Movement trials were extracted in the time window of [-3 3] s where $0 \mathrm{~s}$ is the movement onset computed from EMG signals. Trials with electrooculography (EOG) artifacts were excluded by using a threshold of $120 \mu \mathrm{V}$. Data processing was done offline using MATLAB software (R2014b).

\subsection{MRCP features}

Ten temporal features from the initial negative drift prior to movement onset were extracted from single trials of EEG signals as pre-movement features and one feature from the re-afferent part of these trials was used as the post-movement variable. The time domains of these features are represented in Fig.4c. The amplitude of the peak negativity and the time of peak negativity were considered as the initial features since the other nine features were computed with regards to the time of peak negativity. The average amplitude of single trials in two time ranges with regards to movement onset were extracted: [-1.5 $0.5] \mathrm{s}$ (representing the preparation) and [-0.5 0] s (representing the movement) referred to as the first negativity drift and the second negativity drift respectively (Hallett, 1994). The MRCP variability, defined as the standard deviation among trials of each block and pre-phase slopes attained from linear regression on each single trial were extracted in three time intervals: [-2 
1 1 $] \mathrm{s},\left[\begin{array}{ll}-1 & 0\end{array}\right] \mathrm{s}$ and $[-20] \mathrm{s}$ while $0 \mathrm{~s}$ is time of peak negativity. These time intervals were selected for the analysis based on 2 previous studies where parameters associated to movement execution, such as force and speed, were decoded from the MRCP 3 prior to movement onset (Jochumsen et al., 2013; Xu et al., 2014). The rebound rate defined as the linear regression in the 4 range of [0 1] $\mathrm{s}$ in relation to the time of peak negativity was the re-afferent feature.

5 The Locality Preserving Projection (LPP) method followed by a linear discriminant analyses (LDA) classifier (LPP-LDA) 6 was used to extract movement detection parameters from EEG epochs. The details of this technique are provided elsewhere 7 (Xu et al., 2014). Detection latency (DL) defined as the difference between movement detection time and real movement 8 onset extracted from output of bipolar EMG signals. True positive rate (TPR) that is the number of true detections divided by 9 total true events and false positive rate (FPR) calculated as the number of false detections divided by the number of total 10 events were used as the detection features.

\subsection{Statistics}

Two-way repeated measures analysis of variance (rmANOVA) was selected for statistical analysis of ERP components with 'movement blocks' and 'task demand' as within subject factors and movement blocks as the repeated independent factor. The amplitude of the P300 was considered as the response factor and task demand with two levels (Control and SDT or Control and CDT) and movement blocks with three levels (Block 1, Block 2 and Block 3) were defined as the independent variables. To investigate the differences of P300 amplitude and EMG correlation in each level between two groups, group with two levels (SDT and CDT) was used as the between subject factor in rmANOVA. The same method of two-way rmANOVA was also applied on EMG correlation when 'movement blocks' with three levels and 'task demand' with two levels considered as independent factors.

Temporal features of each single channel were compared using the same method of two-way repeated measures ANOVA with 'movement blocks' (Block 1, Block 2 and Block 3) and 'task demand' (Control and SDT or Control and CDT) considered as independent factors. A rmANOVA was used for each channel separately since the aim was to identify which channels were influenced by attention variations in dual-task conditions. Normality was confirmed according to the Shapiro-Wilk test. Bonferroni correction method was applied due to large number of comparisons and thus response factors were considered significant if $\mathrm{P}<0.004$.

\section{Conclusion}

To have reliable and robust real-time BCIs, it is required to adapt them with users' state such as attention. Attention variations should be monitored since neuroplasticity induction is dependent on this factor. The allocation of attention has differential effects on specific MRCP parameters during dual-task performance with different levels of complexity. Attention was allocated to the task with the higher demand as in the dual-task condition the P300 amplitude of the auditory cue was increased but based on the visual cue was reduced. The more complex task had a significantly greater effect on the MRCP parameters 
1 results suggest that specific features of the MRCP can be implemented to detect changes in the attention of the user, 2 specifically at different levels of task complexity.

\section{Acknowledgement}

4 This research did not receive any specific grant from funding agencies in the public, commercial, or not-for-profit sectors.

5

6

7

8

9

10

11

12

13

14

15

16

17

18

19

20

21

22

23

References 
Aliakbaryhosseinabadi, S., Jiang, N., Petrini, L., Farina, D., Dremstrup, K., Mrachacz-Kersting, N., 2015. Robustness of movement detection techniques from motor execution: Single trial movement related cortical potential. $7^{\text {th }}$ international IEEE/EMBS Conference on Neural Engineering (NER), 2015, 13-16.

4

Aliakbaryhosseinabadi, S., Kamavuako, E. N., Jiang, N., Farina, D., Mrachacz-Kersting, N., 2017. Classification of EEG signals to identify variations in attention during motor task execution. J. Neurosci. Methods. 284, $27-34$.

Aliakbaryhosseinabadi, S., Kostic, V., Pavlovic, A., Radovanovic, S., Nlandu Kamavuako, E., Jiang, N., et al., 2017. Influence of attention alternation on movement-related cortical potentials in healthy individuals and stroke patients. Clin. Neurophysiol., $128,165-175$.

Mrachacz-Kersting, N., Stevenson, A. J.T., Aliakbaryhosseinabadi, S., Lundgaard, A.C., Jørgensen, H.R., Severinsen, K., et al., 2017. An associative brain-computer-interface for acute stroke patients. in Converging clinical and engineering research on neurorehabilitation II: Proceeding of the $3^{\text {rd }}$ International Conference on Neurorehabilitation (ICNR2016)(Segovia: Springer International Publishing), 841-845.

Bruckmann, S., Hauk, D., Roessner, V., Resch, F., Freitag, C. M., Kammer, T., et al., 2012. Cortical inhibition in attention deficit hyperactivity disorder: New insights from the electroencephalographic response to transcranial magnetic stimulation. Brain, 135, 2215-2230.

Casimo, K., Weaver, K. E., Wander, J., Ojemann, J. G., 2017. BCI use and its relation to adaptation in cortical networks. IEEE Trans. Neural Syst. Rehabil. Eng.

Conte, A., Gilio, F., Iezzi, E., Frasca, V., Inghilleri, M., Berardelli, A., 2007. Attention influences the excitability of cortical motor areas in healthy humans. Exp. Brain Res., 182, 109-117.

da Silva-Sauer, L., Valero-Aguayo, L., de la Torre-Luque, A., Ron-Angevin, R., Varona-Moya, S., 2016. Concentration on performance with P300-based BCI systems: A matter of interface features. Appl. Ergon., 52, 325-332.

Diez, P. F., Correa, A. G., Orosco, L., Laciar, E., Mut, V., 2015. Attention-level transitory response: A novel hybrid BCI approach. J. Neural Eng., 12, 056007.

Dirnberger, G., Reumann, M., Endl, W., Lindinger, G., Lang, W., Rothwell, J. C., 2000. Dissociation of motor preparation from memory and attentional processes using movement-related cortical potentials. Exp. Brain Res., 135, $231-240$.

Falvo, M. J., Sirevaag, E. J., Rohrbaugh, J. W., Earhart, G. M., 2010. Resistance training induces supraspinal adaptations: Evidence from movement-related cortical potentials. Eur. J. Appl. Physiol., 109, 923-933.

Falvo, M. J., Sirevaag, E. J., Rohrbaugh, J. W., Earhart, G. M., 2011. Central adaptations to repetitive grasping in healthy aging. Brain Topogr., 24, 292-301.

Grill-Spector, K., Henson, R., Martin, A., 2006. Repetition and the brain: Neural models of stimulus-specific effects. Trends Cogn. Sci., 10, 14-23.

Hallett, M., 1994. Movement-related cortical potentials. Electromyogr. Clin. Neurophysiol., 34, 5-13.

Hebb, D. O., 2002.The organization of behavior: A neuropsychological theory. Mahwah, N.J. ; L. Erlbaum Associates.

Hoffman, J. E., Houck, M. R., MacMillan, F. W., Simons, R. F., Oatman, L. C., 1985. Event-related potentials elicited by automatic targets: A dual-task analysis. J. Exp. Psychol. Hum. Percep. Perform., 11, 50-61. 
1 Huang, W., Chen, W., Zhang, X., 2015. The neurophysiology of P 300--an integrated review. Eur. Rev. Med. Pharmacol.

2 Sci., 19, 1480-1488.

3 Jeon, Y., Polich, J., 2003. Meta-analysis of P300 and schizophrenia: Patients, paradigms, and practical implications.

4 Psychophysiology, 40, 684-701.

5 Jochumsen, M., Niazi, I. K., Mrachacz-Kersting, N., Farina, D., Dremstrup, K., 2013. Detection and classification of 6 movement-related cortical potentials associated with task force and speed. J. Neural Eng., 10, 056015.

7 Jochumsen, M., Niazi, I. K., Rovsing, H., Rovsing, C., Nielsen, G. A. R., Andersen, T. K., et al., 2014. Detection of movement 8 intentions through a single channel of electroencephalography. Proceedings of the 2nd international conference on 9 NeuroRehabilitation (ICNR2014), 2014, 465-472.

Jochumsen, M., Niazi, I. K., Taylor, D., Farina, D., Dremstrup, K., 2015. Detecting and classifying movement-related cortical potentials associated with hand movements in healthy subjects and stroke patients from single-electrode, single-trial EEG. J. Neural Eng., 12, 056013.

Katayama, J., Polich, J., 1999. Auditory and visual P300 topography from a 3 stimulus paradigm. Clin. Neurophysiol, 110, 463-468.

Kida, T., Nishihira, Y., Hatta, A., Wasaka, T., Tazoe, T., Sakajiri, Y., et al., 2004. Resource allocation and somatosensory P300 amplitude during dual task: Effects of tracking speed and predictability of tracking direction. Clin. Neurophysiol, 115, 2616-2628.

Kok, A., 2001. On the utility of P3 amplitude as a measure of processing capacity. Psychophysiology, 38, 557-557.

Krusienski, D. J., Sellers, E. W., McFarland, D. J., Vaughan, T. M., Wolpaw, J. R., 2008. Toward enhanced P300 speller performance. J. Neurosci. Methods, 167, 15-21.

Liefooghe, B., Vandierendonck, A., Muyllaert, I., Verbruggen, F., Vanneste, W., 2005. The phonological loop in task alternation and task repetition. Memory, 13, 550-560.

Lin, C., Chen, S., Chiu, T., Lin, H., Ko, L., 2011. Spatial and temporal EEG dynamics of dual-task driving performance. J. Neuroeng. Rehabil., 8, 8-11.

Linden, D. E. J., 2005. The P300: Where in the brain is it produced and what does it tell us? Neuroscientist, 11, 563-576.

Melinscak, F., Montesano, L., Minguez, J., 2016. Asynchronous detection of kinesthetic attention during mobilization of lower limbs using EEG measurements. J. Neural Eng., 13, 016018.

Montani, V., De Filippo De Grazia, M., Zorzi, M., 2014. A new adaptive videogame for training attention and executive functions: Design principles and initial validation. Front. Psychol., 5, 409.

Mrachacz-Kersting, N., Jiang, N., Thomas Stevenson, A. J., Niazi, I. K., Kostic, V., Pavlovic, A., et al., 2016. Efficient neuroplasticity induction in chronic stroke patients by an associative brain-computer interface. J. Neurophysiol., 115, 14101421.

Murray, N. P., Janelle, C. M., 2007. Event-related potential evidence for the processing efficiency theory. J. Sports Sci., 25, $161-171$. 
1 Myrden, A., Chau, T., 2017. A passive EEG-BCI for single-trial detection of changes in mental state. IEEE Trans. Neural

2 Syst. Rehabil. Eng., 25, 345-356.

3 Nash, A. J., Fernandez, M., 1996. P300 and allocation of attention in dual-tasks. Int. J. Psychophysiol., 23, 171-180.

4 Oknina, L. B., Kuznetsova, O. A., Belostostskiî, A. P., Nechaeva, N. L., Kutakova, E. V., Masherov, E. L., Romanov, A. S.

5 2011. Amplitude-time parameters of long-latency components (N1, N2 and P300) of acoustic evoked potential of healthy 6 examinees of young and mature age. Fiziol. Cheloveka, 37, 56-64.

7 O'Sullivan, J. A., Power, A. J., Mesgarani, N., Rajaram, S., Foxe, J. J., Shinn-Cunningham, B. G., et al., 2015. Attentional 8 selection in a cocktail party environment can be decoded from single-trial EEG. Cereb. Cortex, 25, 1697-1706.

Pascual-Leone, A., Grafman, J., Hallett, M., 1994. Modulation of cortical motor output maps during development of implicit and explicit knowledge. Science, 263, 1287-1289.

Pineda, J. A., Silverman, D. S., Vankov, A., Hestenes, J., 2003. Learning to control brain rhythms: making a brian computer interface possible. IEEE Trnas. Neural Syst. Rehabil. Eng., 11, 181-184.

Polich, J., 1987. Task difficulty, probability, and inter-stimulus interval as determinants of P300 from auditory stimuli. Electroencephalogr. Clin. Neurophysiol., 68, 311-320.

Polich, J., 2007. Updating P300: An integrative theory of P3a and P3b. Clin. Neurophysiol., 118, 2128-2148.

Stefan, K., Wycislo, M., Classen, J., 2004a. Modulation of associative human motor cortical plasticity by attention. J. 19 Neurophysiol., 92, 66-72.

Stopford, C. L., Thompson, J. C., Neary, D., Richardson, A. M. T., Snowden, J. S., 2012. Working memory, attention, and executive function in alzheimer's disease and frontotemporal dementia. Cortex, 48, 429-446. $1187-1188$.

Teillet, S., Lotte, F., N'Kaoua, B., Jeunet, C., 2016. Towards a spatial ability training to improve mental imagery based braincomputer interface (MI-BCI) performance: A pilot study. The Institute of Electrical and Electronics Engineers, Inc. IEEE Conference Proceedings on Systems, Man, and Cybernetics (SMC), 2016, 003664-003669.

Xu, M., Qi, H., Wan, B., Yin, T., Liu, Z., Ming, D., 2013. A hybrid BCI speller paradigm combining P300 potential and the SSVEP blocking feature. J. Neural Eng., 10, 026001.

Xu, R., Jiang, N., Lin, C., Mrachacz-Kersting, N., Dremstrup, K., Farina, D., 2014. Enhanced low-latency detection of motor intention from EEG for closed-loop brain-computer interface applications. IEEE Trans. Biomed. Eng., 61, 288-296. 
1 Fig. 1. A diagram of different stages of the experiment. Two groups were conducted within the test when each group has to 2 do a simple dorsiflexion with/without executing an oddball task. The oddball task is counting the number of a single tone 3 among three different tones (SDT) or counting the number of a defined sequence of three different tones (CDT).

4 Fig. 2. Event-related potentials obtained from channel $\mathrm{Cz}$ for one participant according to the visual stimulus for (a) Control5 SDT and (c) Control-CDT. ERP wave obtained from the same participant in response to the auditory stimulus shown in (b) 6 Control-SDT and (d) Control-CDT. The grand average of the P300 amplitude in both conditions of Control-SDT and Control7 CDT is illustrated in (e) according to the visual cue and (f) based on the auditory cue. (*) indicates significant differences.

8 Fig. 3. Grand average of MRCP from all participants obtained from nine single channels in (a) simple dual task and (b) 9 complex dual task. Differences are more often detected for the channels over the motor cortex and fronto-midline than for the parietal channels. The difference between tasks is more evident when comparing the simple and the most difficult dual tasks.

Fig. 4. (a) Experimental paradigm during movement recording, which consisted of five time phases. After 2-3 sec of focus time a cursor traveling along a line for $2 \mathrm{sec}$ appeared. When the cursor reaches to the ramp, participants had to start movement execution and hold it for $2 \mathrm{sec}$. At the end, 3-5 sec rest time was provided between trials. (b) Illustration of different tones of low, middle and high pitch used in auditory oddball cue. (c) Representation of different time domains of extracted features form single trial EEG signals. Time of peak negativity and amplitude of peak negativity were selected at the point of most negativity of single trials. $\mathrm{D}_{10}, \mathrm{D}_{20}$ and $\mathrm{D}_{21}$ represent different time domains respect to the time of peak negativity for extracting pre- slope and pre-variability. RR is the rebound rate that was measured in range of $1 \mathrm{sec}$ after time of peak negativity.

Table 1. Statistical different temporal features in nine channels within both experiments. Dark gray parts indicate significant channels between control and CDT level. Light gray areas show significant channels between control and SDT level.

Table 2. Detection parameters with statistical differences within both experiments. Dark gray parts indicate significant channels between control and CDT level. Light gray areas show significant channels between control and SDT level. 


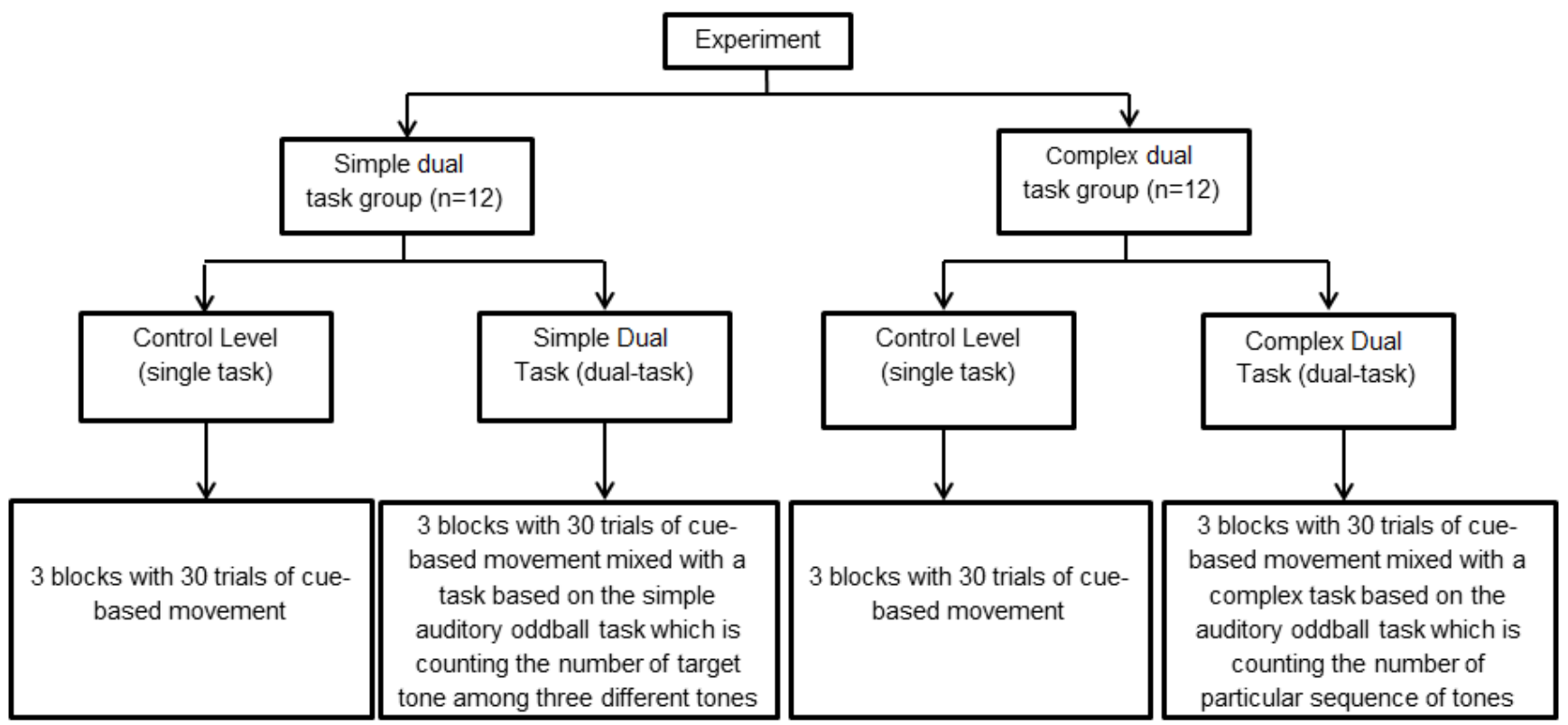

2 Fig. 1. A diagram of different stages of the experiment. Two groups were conducted within the test when each group has to do a simple

3 dorsiflexion with/without executing an oddball task. The oddball task is counting the number of a single tone among three different tones

4 (SDT) or counting the number of a defined sequence of three different tones (CDT). 


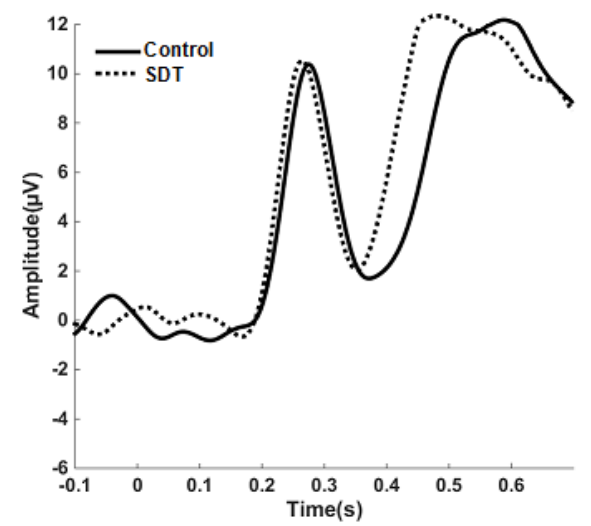

(a)

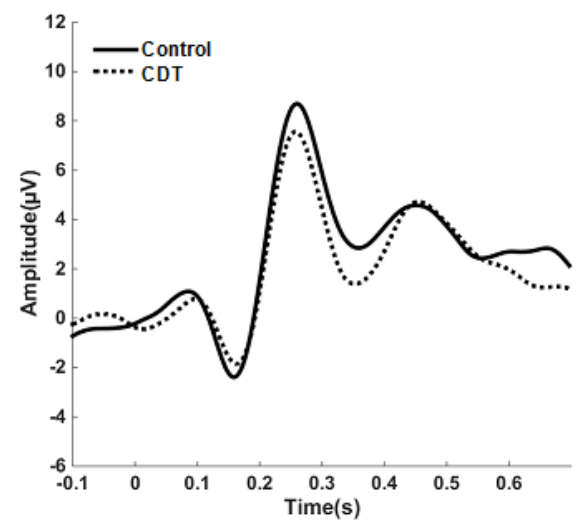

(c)

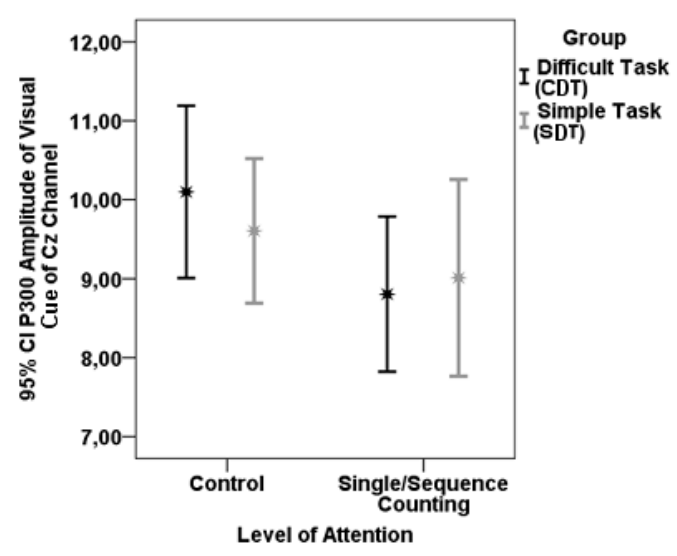

(e)

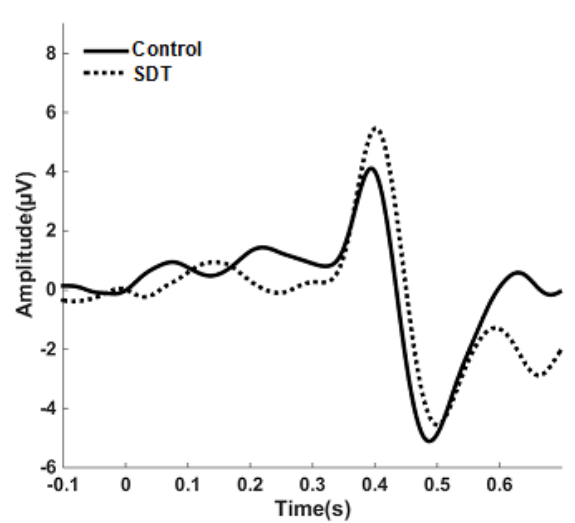

(b)

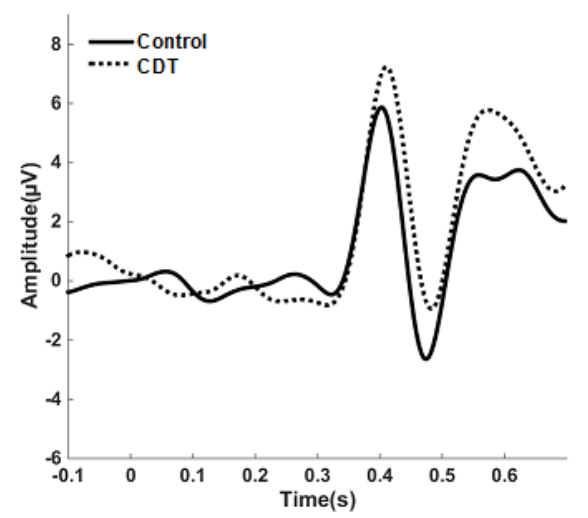

(d)

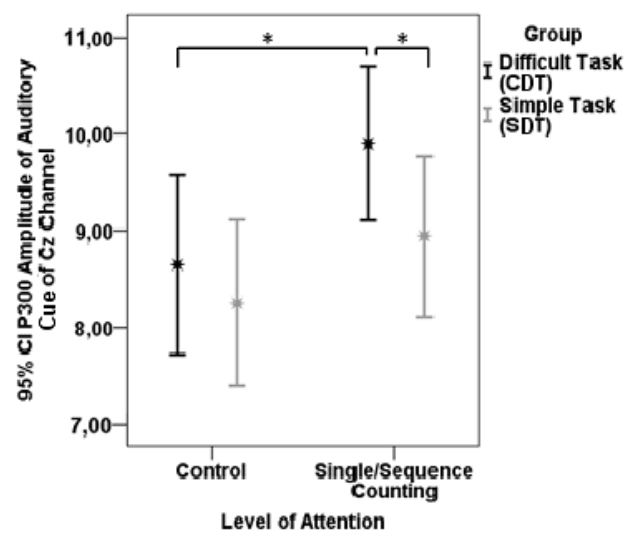

(f)

3

4 Fig. 2. Event-related potentials obtained from channel $\mathrm{Cz}$ for one participant according to the visual stimulus for (a) Control-SDT and (c) 5 Control-CDT. ERP wave obtained from the same participant in response to the auditory stimulus shown in (b) Control-SDT and (d) Control6 CDT. The grand average of the P300 amplitude in both conditions of Control-SDT and Control-CDT is illustrated in (e) according to the $7 \quad$ visual cue and (f) based on the auditory cue. $(*)$ indicates significant differences. 


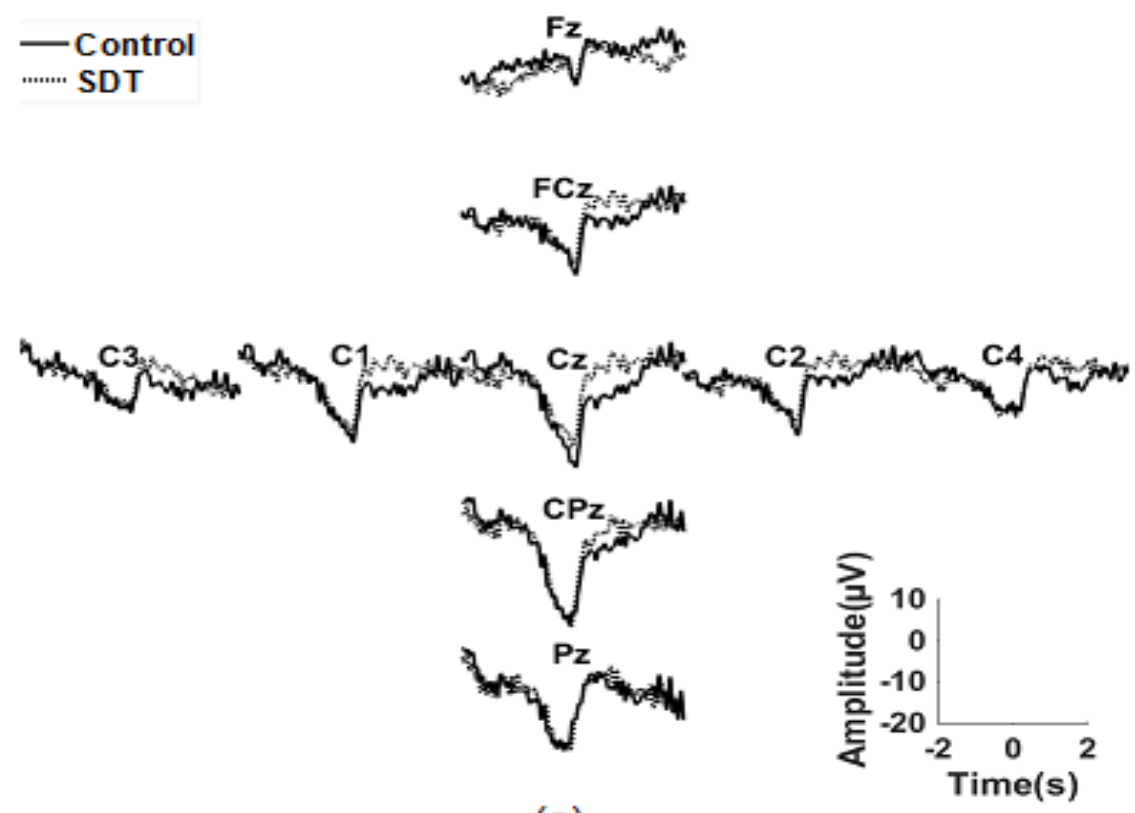

(a)
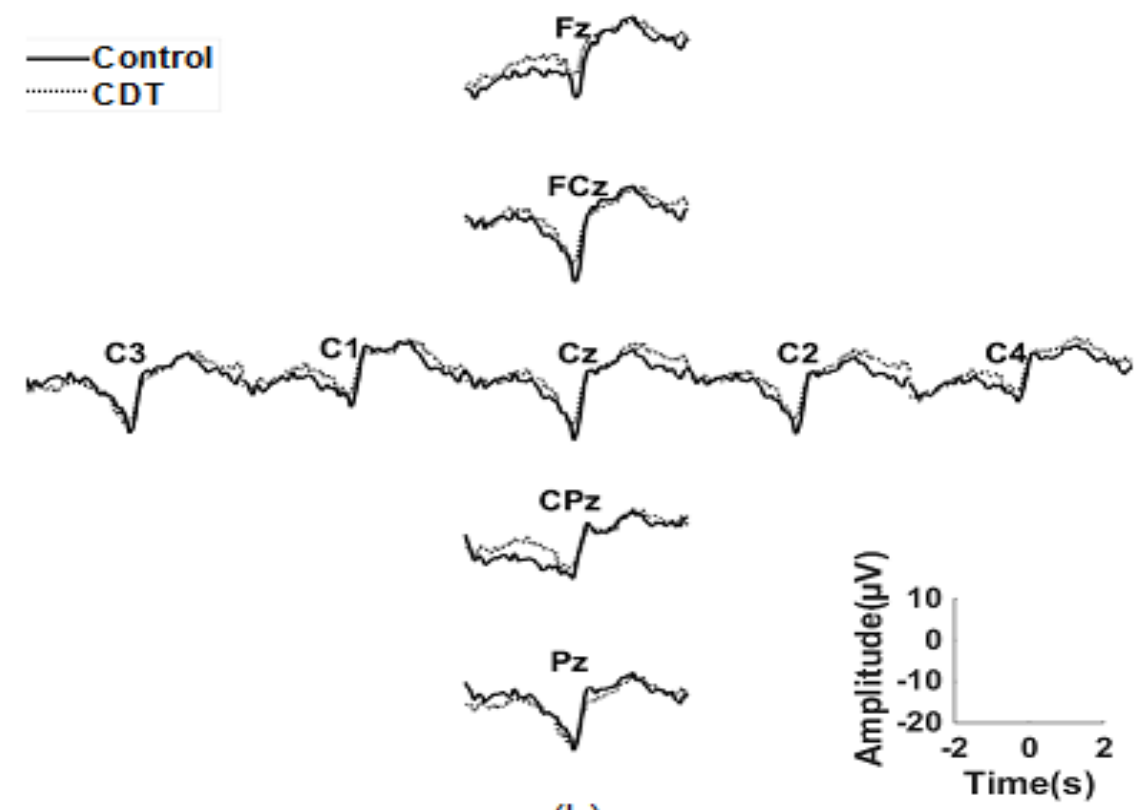

2

(b)

3 Fig. 3. Grand average of MRCP from all participants obtained from nine single channels in (a) simple dual task and (b) complex 4 dual task. Differences are more often detected for the channels over the motor cortex and fronto-midline than for the parietal 5 channels. The difference between tasks is more evident when comparing the simple and the most difficult dual tasks. 

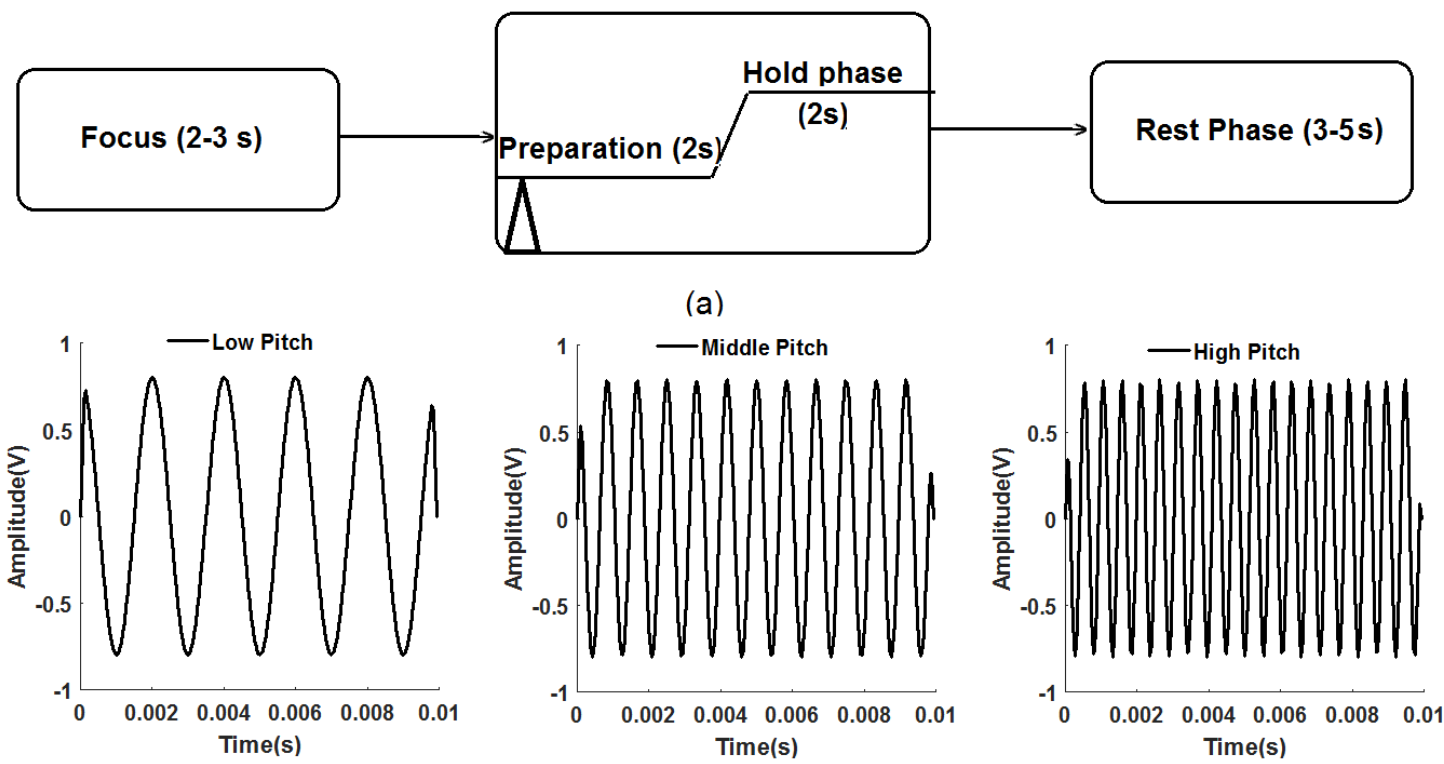

(b)

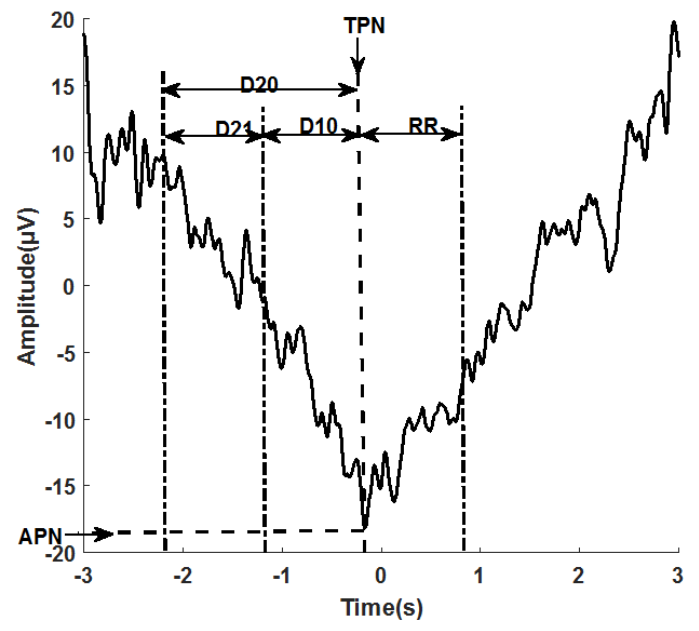

(c)

4 Fig. 4. (a) Experimental paradigm during movement recording, which consisted of five time phases. After 2-3 sec of focus time a cursor 5 traveling along a line for $2 \mathrm{sec}$ appeared. When the cursor reaches to the ramp, participants had to start movement execution and hold it for $2 \mathrm{sec}$. At the end, 3-5 sec rest time was provided between trials. (b) Illustration of different tones of low, middle and high pitch used in auditory oddball cue. (c) Representation of different time domains of extracted features form single trial EEG signals. Time of peak negativity and amplitude of peak negativity were selected at the point of most negativity of single trials. $\mathrm{D}_{10}, \mathrm{D}_{20}$ and $\mathrm{D}_{21}$ represent different time domains respect to the time of peak negativity for extracting pre- slope and pre-variability. RR is the rebound rate that was measured in range of $1 \mathrm{sec}$ after time of peak negativity. 
4 Table 1.

5 Statistical different temporal features in nine channels within both experiments. Dark gray parts indicate significant channels between

6 control and CDT level. Light gray areas show significant channels between control and SDT level.

\begin{tabular}{|c|c|c|c|c|c|c|c|c|c|c|c|}
\hline & & & $\mathbf{F z}$ & FCz & $\mathbf{C 3}$ & $\mathrm{C1}$ & $\mathrm{Cz}$ & C2 & C4 & $\mathrm{CPz}$ & $\mathbf{P z}$ \\
\hline \multirow{4}{*}{$\begin{array}{l}\text { AMPLITUDE } \\
\text { OF PEAK } \\
\text { NEGATIVITY }\end{array}$} & \multirow[b]{2}{*}{$\begin{array}{l}\text { Control- } \\
\text { CDT }\end{array}$} & Control & $\begin{array}{l}-19.1 \\
\mu \mathrm{V}\end{array}$ & $\begin{array}{l}-21.1 \\
\mu \mathrm{V}\end{array}$ & $\begin{array}{l}-20.1 \\
\mu V\end{array}$ & $\begin{array}{l}-20.5 \\
\mu V\end{array}$ & $\begin{array}{l}-22.1 \\
\mu \mathrm{V}\end{array}$ & $\begin{array}{l}-21.1 \\
\mu \mathrm{V}\end{array}$ & $\begin{array}{l}-18.2 \\
\mu V\end{array}$ & $\begin{array}{l}-20.5 \\
\mu \mathrm{V}\end{array}$ & $\begin{array}{l}-20.5 \\
\mu \mathrm{V}\end{array}$ \\
\hline & & CDT & $\begin{array}{l}-18.5 \\
\mu \mathrm{V}\end{array}$ & $\begin{array}{l}-18 \\
\mu V\end{array}$ & $\begin{array}{l}-16.9 \\
\mu \mathrm{V}\end{array}$ & $\begin{array}{l}-18.6 \\
\mu \mathrm{V}\end{array}$ & $\begin{array}{l}-19.3 \\
\mu \mathrm{V}\end{array}$ & $\begin{array}{l}-17.9 \\
\mu \mathrm{V}\end{array}$ & $\begin{array}{l}-14.7 \\
\mu \mathrm{V}\end{array}$ & $\begin{array}{l}-17.1 \\
\mu \mathrm{V}\end{array}$ & $\begin{array}{l}-19.2 \\
\mu \mathrm{V}\end{array}$ \\
\hline & \multirow[t]{2}{*}{$\begin{array}{l}\text { Control- } \\
\text { SDT }\end{array}$} & Control & $\begin{array}{l}-15.6 \\
\mu \mathrm{V}\end{array}$ & $\begin{array}{l}-18.2 \\
\mu \mathrm{V}\end{array}$ & $\begin{array}{l}-18.3 \\
\mu \mathrm{V}\end{array}$ & $\begin{array}{l}-18.5 \\
\mu \mathrm{V}\end{array}$ & $\begin{array}{l}-21.7 \\
\mu \mathrm{V}\end{array}$ & $\begin{array}{l}-16.9 \\
\mu \mathrm{V}\end{array}$ & $\begin{array}{l}-15.4 \\
\mu \mathrm{V}\end{array}$ & $\begin{array}{l}-18.1 \\
\mu \mathrm{V}\end{array}$ & $\begin{array}{l}-17.8 \\
\mu \mathrm{V}\end{array}$ \\
\hline & & SDT & $\begin{array}{l}-16.8 \\
\mu \mathrm{V}\end{array}$ & $\begin{array}{l}-15.8 \\
\mu \mathrm{V}\end{array}$ & $\begin{array}{l}-18.7 \\
\mu \mathrm{V}\end{array}$ & $\begin{array}{l}-17.3 \\
\mu V\end{array}$ & $\begin{array}{l}-18.6 \\
\mu V\end{array}$ & $\begin{array}{l}-13.7 \\
\mu \mathrm{V}\end{array}$ & $\begin{array}{l}-18.1 \\
\mu \mathrm{V}\end{array}$ & $-17 \mu \mathrm{V}$ & $\begin{array}{l}-17.3 \\
\mu \mathrm{V}\end{array}$ \\
\hline \multirow{4}{*}{ SCNV } & \multirow{2}{*}{$\begin{array}{l}\text { Control- } \\
\text { CDT }\end{array}$} & Control & $\begin{array}{l}-5.8 \\
\mu \mathrm{V}\end{array}$ & $\begin{array}{l}-7.7 \\
\mu \mathrm{V}\end{array}$ & $\begin{array}{l}-5 \\
\mu \mathrm{V}\end{array}$ & $\begin{array}{l}-7.1 \\
\mu \mathrm{V}\end{array}$ & $\begin{array}{r}-9.8 \\
\mu \mathrm{V}\end{array}$ & $\begin{array}{l}-7.2 \\
\mu \mathrm{V}\end{array}$ & $\begin{array}{l}-5.2 \\
\mu \mathrm{V}\end{array}$ & $\begin{array}{l}-5.2 \\
\mu \mathrm{V}\end{array}$ & $\begin{array}{l}-3.4 \\
\mu \mathrm{V}\end{array}$ \\
\hline & & CDT & $\begin{array}{l}-6.1 \\
\mu \mathrm{V}\end{array}$ & $\begin{array}{l}-5.4 \\
\mu \mathrm{V}\end{array}$ & $\begin{array}{l}-3.3 \\
\mu \mathrm{V}\end{array}$ & $\begin{array}{l}-5 \\
\mu \mathrm{V}\end{array}$ & $\begin{array}{l}-7.7 \\
\mu \mathrm{V}\end{array}$ & $\begin{array}{l}-5.3 \\
\mu \mathrm{V}\end{array}$ & $\begin{array}{l}-3.2 \\
\mu \mathrm{V}\end{array}$ & $\begin{array}{l}-3.8 \\
\mu \mathrm{V}\end{array}$ & $\begin{array}{l}-2.3 \\
\mu \mathrm{V}\end{array}$ \\
\hline & \multirow{2}{*}{$\begin{array}{l}\text { Control- } \\
\text { SDT }\end{array}$} & Control & $\begin{array}{l}-2.6 \\
\mu \mathrm{V}\end{array}$ & $\begin{array}{l}-4.8 \\
\mu \mathrm{V}\end{array}$ & $\begin{array}{l}-4.5 \\
\mu \mathrm{V}\end{array}$ & $\begin{array}{r}-5.7 \\
\mu \mathrm{V}\end{array}$ & $\begin{array}{l}-7.5 \\
\mu \mathrm{V}\end{array}$ & $\begin{array}{l}-5.3 \\
\mu \mathrm{V}\end{array}$ & $\begin{array}{l}-4.4 \\
\mu \mathrm{V}\end{array}$ & $\begin{array}{l}-5.7 \\
\mu \mathrm{V}\end{array}$ & $\begin{array}{l}-4.3 \\
\mu \mathrm{V}\end{array}$ \\
\hline & & $\begin{array}{l}\text { SDT } \\
\end{array}$ & $\begin{array}{l}-2.2 \\
\mu \mathrm{V}\end{array}$ & $\begin{array}{l}-3.6 \\
\mu \mathrm{V}\end{array}$ & $\begin{array}{l}-4 \\
\mu \mathrm{V}\end{array}$ & $\begin{array}{l}-4.5 \\
\mu \mathrm{V}\end{array}$ & $\begin{array}{l}-5.7 \\
\mu \mathrm{V}\end{array}$ & $\begin{array}{l}-3.3 \\
\mu \mathrm{V}\end{array}$ & $\begin{array}{l}-4.6 \\
\mu \mathrm{V}\end{array}$ & $\begin{array}{l}-4.8 \\
\mu \mathrm{V}\end{array}$ & $\begin{array}{l}-4.3 \\
\mu \mathrm{V}\end{array}$ \\
\hline \multirow{4}{*}{ S20 } & \multirow{2}{*}{$\begin{array}{l}\text { Control- } \\
\text { CDT }\end{array}$} & Control & $\begin{array}{l}-2.6 \\
\mu \mathrm{V} / \mathrm{s}\end{array}$ & $\begin{array}{l}-4.7 \\
\mu \mathrm{V} / \mathrm{s}\end{array}$ & $\begin{array}{l}-3.8 \\
\mu \mathrm{V} / \mathrm{s}\end{array}$ & $\begin{array}{l}-4.3 \\
\mu \mathrm{V} / \mathrm{s}\end{array}$ & $\begin{array}{l}-5.5 \\
\mu \mathrm{V} / \mathrm{s}\end{array}$ & $\begin{array}{l}-4.5 \\
\mu \mathrm{V} / \mathrm{s}\end{array}$ & $\begin{array}{l}-4.1 \\
\mu \mathrm{V} / \mathrm{s}\end{array}$ & $\begin{array}{l}-3.7 \\
\mu \mathrm{V} / \mathrm{s}\end{array}$ & $\begin{array}{l}-4.1 \\
\mu \mathrm{V} / \mathrm{s}\end{array}$ \\
\hline & & CDT & $\begin{array}{l}2.4 \\
\mu \mathrm{V} / \mathrm{s}\end{array}$ & $\begin{array}{l}-3.6 \\
\mu \mathrm{V} / \mathrm{s}\end{array}$ & $\begin{array}{l}-3.6 \\
\mu \mathrm{V} / \mathrm{s}\end{array}$ & $\begin{array}{l}-3.2 \\
\mu \mathrm{V} / \mathrm{s}\end{array}$ & $\begin{array}{l}-4.3 \\
\mu \mathrm{V} / \mathrm{s}\end{array}$ & $\begin{array}{l}-4.2 \\
\mu \mathrm{V} / \mathrm{s}\end{array}$ & -3.1 & $\begin{array}{l}-3.6 \\
\mu \mathrm{V} / \mathrm{s}\end{array}$ & $\begin{array}{l}-3.4 \\
\mu \mathrm{V} / \mathrm{s}\end{array}$ \\
\hline & \multirow{2}{*}{$\begin{array}{l}\text { Control- } \\
\text { SDT }\end{array}$} & Control & $\begin{array}{l}-2.3 \\
\mu \mathrm{V} / \mathrm{s}\end{array}$ & $\begin{array}{l}-3.1 \\
\mu \mathrm{V} / \mathrm{s}\end{array}$ & $\begin{array}{l}-3.2 \\
\mu \mathrm{V} / \mathrm{s}\end{array}$ & $\begin{array}{l}-3.7 \\
\mu \mathrm{V} / \mathrm{s}\end{array}$ & $\begin{array}{l}-4.6 \\
\mu \mathrm{V} / \mathrm{s}\end{array}$ & $\begin{array}{l}-3.5 \\
\mu \mathrm{V} / \mathrm{s}\end{array}$ & $\begin{array}{l}-4.7 \\
\mu \mathrm{V} / \mathrm{s}\end{array}$ & $\begin{array}{l}-4.1 \\
\mu \mathrm{V} / \mathrm{s}\end{array}$ & $\begin{array}{l}-3.9 \\
\mu \mathrm{V} / \mathrm{s}\end{array}$ \\
\hline & & $\begin{array}{l}\text { SDT } \\
\end{array}$ & $-3 \mu \mathrm{V} / \mathrm{s}$ & $\begin{array}{l}-3 \\
\mu \mathrm{V} / \mathrm{s}\end{array}$ & $\begin{array}{l}-3.7 \\
\mu \mathrm{V} / \mathrm{s}\end{array}$ & $\begin{array}{l}-4 \\
\mu \mathrm{V} / \mathrm{s}\end{array}$ & $\begin{array}{l}-4.5 \\
\mu \mathrm{V} / \mathrm{s}\end{array}$ & $\begin{array}{l}-3.3 \\
\mu \mathrm{V} / \mathrm{s}\end{array}$ & $\begin{array}{l}-3.9 \\
\mu \mathrm{V} / \mathrm{s}\end{array}$ & $\begin{array}{l}-4.3 \\
\mu \mathrm{V} / \mathrm{s}\end{array}$ & $\begin{array}{l}-4.2 \\
\mu \mathrm{V} / \mathrm{s}\end{array}$ \\
\hline
\end{tabular}

7 
4 Table 2.

5 Detection parameters with statistical differences within both experiments. Dark gray parts indicate significant channels between control and

6 CDT level. Light gray areas show significant channels between control and SDT level.

\begin{tabular}{|c|c|c|c|c|c|c|c|c|c|c|c|}
\hline & & & $\mathbf{F z}$ & FCz & $\mathrm{C3}$ & C1 & $\mathrm{Cz}$ & $\mathrm{C2}$ & C4 & $\mathrm{CPz}$ & $\mathbf{P z}$ \\
\hline \multirow{4}{*}{ DL } & \multirow{2}{*}{$\begin{array}{l}\text { Control- } \\
\text { CDT }\end{array}$} & Control & $\begin{array}{l}224.6 \\
\mathrm{~ms}\end{array}$ & $\begin{array}{l}234.1 \\
\mathrm{~ms}\end{array}$ & $\begin{array}{l}231.7 \\
\mathrm{~ms}\end{array}$ & $\begin{array}{l}234.7 \\
\mathrm{~ms}\end{array}$ & $\begin{array}{l}233.3 \\
\mathrm{~ms}\end{array}$ & $\begin{array}{l}234 \\
\mathrm{~ms}\end{array}$ & $\begin{array}{l}235.1 \\
\mathrm{~ms}\end{array}$ & $\begin{array}{l}234.1 \\
\mathrm{~ms}\end{array}$ & $\begin{array}{l}239 \\
\mathrm{~ms}\end{array}$ \\
\hline & & CDT & $\begin{array}{l}244.5 \\
\mathrm{~ms}\end{array}$ & $\begin{array}{l}239.7 \\
\mathrm{~ms}\end{array}$ & $\begin{array}{l}252.2 \\
\mathrm{~ms}\end{array}$ & $\begin{array}{l}252.7 \\
\mathrm{~ms}\end{array}$ & $250 \mathrm{~ms}$ & $\begin{array}{l}250.1 \\
\mathrm{~ms}\end{array}$ & $\begin{array}{l}242.5 \\
\mathrm{~ms}\end{array}$ & $254 \mathrm{~ms}$ & $\begin{array}{l}246.1 \\
\mathrm{~ms}\end{array}$ \\
\hline & \multirow{2}{*}{$\begin{array}{l}\text { Control- } \\
\text { SDT }\end{array}$} & Control & $\begin{array}{l}227.9 \\
\mathrm{~ms}\end{array}$ & $\begin{array}{l}235.1 \\
\mathrm{~ms}\end{array}$ & $\begin{array}{l}238.5 \\
\mathrm{~ms}\end{array}$ & $\begin{array}{l}238.4 \\
\mathrm{~ms}\end{array}$ & $\begin{array}{l}237.4 \\
\mathrm{~ms}\end{array}$ & $\begin{array}{l}235.7 \\
\mathrm{~ms}\end{array}$ & $\begin{array}{l}236.8 \\
\mathrm{~ms}\end{array}$ & $\begin{array}{l}238.3 \\
\mathrm{~ms}\end{array}$ & $\begin{array}{l}241.3 \\
\mathrm{~ms}\end{array}$ \\
\hline & & SDT & $\begin{array}{l}234.6 \\
\mathrm{~ms}\end{array}$ & $\begin{array}{l}241 \\
\mathrm{~ms}\end{array}$ & $\begin{array}{l}244.7 \\
\mathrm{~ms}\end{array}$ & $\begin{array}{l}250.1 \\
\mathrm{~ms}\end{array}$ & $\begin{array}{l}244.2 \\
\mathrm{~ms}\end{array}$ & $\begin{array}{l}244.6 \\
\mathrm{~ms}\end{array}$ & $\begin{array}{l}241.3 \\
\mathrm{~ms}\end{array}$ & $\begin{array}{l}240.7 \\
\mathrm{~ms}\end{array}$ & $\begin{array}{l}242.6 \\
\mathrm{~ms}\end{array}$ \\
\hline \multirow{4}{*}{ TPR } & \multirow{2}{*}{$\begin{array}{l}\text { Control- } \\
\text { CDT }\end{array}$} & Control & $76 \%$ & $83 \%$ & $82 \%$ & $73 \%$ & $78 \%$ & $83 \%$ & $80 \%$ & $80 \%$ & $78 \%$ \\
\hline & & CDT & $72 \%$ & $78 \%$ & $73 \%$ & $65 \%$ & $68 \%$ & $74 \%$ & $70 \%$ & $76 \%$ & $75 \%$ \\
\hline & \multirow{2}{*}{$\begin{array}{l}\text { Control- } \\
\text { SDT }\end{array}$} & Control & $86 \%$ & $80 \%$ & $79 \%$ & $80 \%$ & $82 \%$ & $79 \%$ & $72 \%$ & $80 \%$ & $79 \%$ \\
\hline & & SDT & $82 \%$ & $71 \%$ & $77 \%$ & $76 \%$ & $71 \%$ & $68 \%$ & $69 \%$ & $76 \%$ & $78 \%$ \\
\hline
\end{tabular}

7 